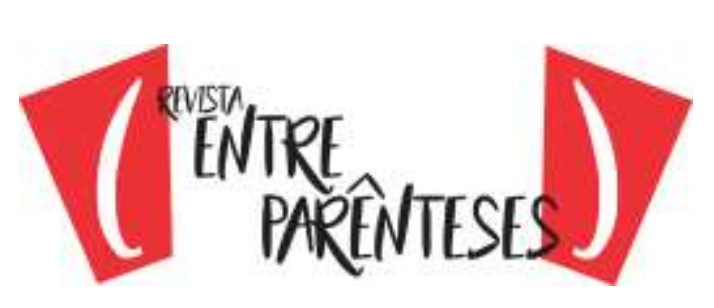

ISSN 2238-4502

\title{
PRECISAMOS FALAR SOBRE ENSINO DE GRAMÁTICA? PERCEPÇÕES E PERSPECTIVAS DA ABORDAGEM GRAMATICAL NO SERIDÓ-RN
}

\author{
Jakeline Simões Gomes \\ Universidade Federal do Rio Grande do Norte \\ (jakegomes@ufrn.edu.br) \\ Nedja Lima de Lucena \\ Universidade Federal do Rio Grande do Norte \\ (nedjalucena@ufrn.edu.br)
}

\begin{abstract}
Resumo
Este trabalho discute aspectos relacionados ao ensino e aprendizagem de gramática no âmbito da Educação Básica na região do Seridó, no estado do Rio Grande de Norte (RN). Para isso, objetivou mapear as discussões e percepções acerca do ensino de gramática oriundas de dissertações produzidas no âmbito do Programa de Mestrado Profissional em Letras. Teoricamente, o estudo baseia-se nas discussões de Travaglia (2002), Antunes (2003), Faraco (2006), Neves (2010), Bispo e Silva (2011), Vieira e Brandão (2019), dentre outros. Os resultados obtidos demonstram que, apesar dos avanços quanto à abordagem do fenômeno gramatical nas aulas de língua portuguesa, percebe-se, ainda, uma dificuldade de atrelar a reflexão gramatical às práticas de leitura e produção de textos.
\end{abstract}

Palavras-chave: Ensino de gramática. Aula de língua portuguesa. Gramática contextualizada.

DOI: https://doi.org/10.32988/rep.v10n1.1269

Dossiê "Possibilidades de trabalho com a Língua Portuguesa"

n. 1

$1-18$




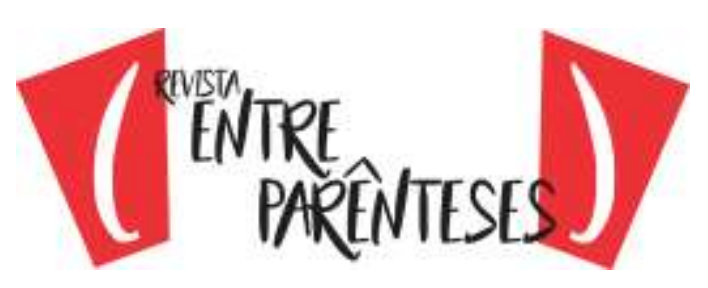

ISSN 2238-4502

\section{Jakeline Simões Gomes}

Graduada em Letras - Língua Portuguesa (2021), pela Universidade Federal do Rio Grande do Norte - UFRN. Atuou como Bolsista de Iniciação Científica - PIBIC/UFRN (2019-2020) na área de Linguística, desenvolvendo estudos sobre a interface entre ensino e gramática. Atuou como Bolsista de Monitoria nas disciplinas de Morfologia e Sintaxe da Língua Portuguesa - UFRN (2020-2021). Membro do Grupo de Estudos Discurso \& Gramática - UFRN.

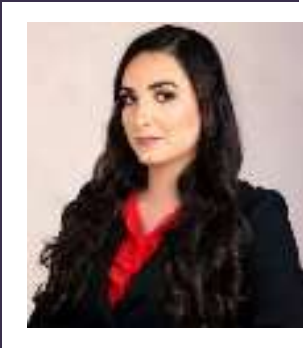

http://lattes.cnpq.br/1423146591089155

https://orcid.org/0000-0001-7849-7246

DOI: https://doi.org/10.32988/rep.v10n1.1269

Dossiê "Possibilidades de trabalho com a Língua Portuguesa"

v. 10

n. 1




\section{Nedja Lima de Lucena}

Graduada em Letras - Língua Portuguesa (2007), Mestre em Estudos da Linguagem (2010) e Doutora em Estudos da Linguagem (2016), na área de Linguística - com foco em Linguística Aplicada, pela Universidade Federal do Rio Grande do Norte (UFRN). É professora adjunta de Língua Portuguesa, na graduação (UFRN), e professora e pesquisadora, na área de Linguística, no Programa de Pós-Graduação em Estudos da Linguagem (PPgEL-UFRN).

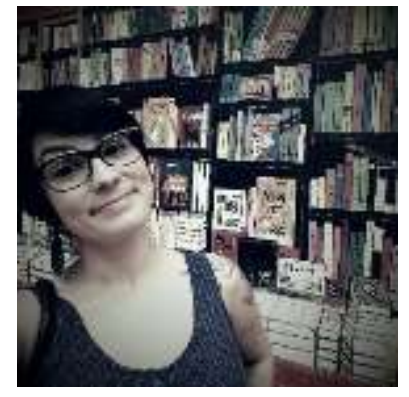
Interessa-se, em especial, por temas afetos à Linguística Funcional Centrada no Uso (interface entre Funcionalismo norte-americano e Linguística Cognitiva), tais como: transitividade; estrutura argumental; tipos semânticos de verbos; relações gramaticais; Gramática de Construções; interface sintaxe-semântica; descrição, análise e reflexão de fenômenos gramaticais e suas implicações para o ensino de Língua Portuguesa. Membro do Grupo de Estudos Discurso \& Gramática - UFRN. Membro do GT Descrição do português da ANPOLL.
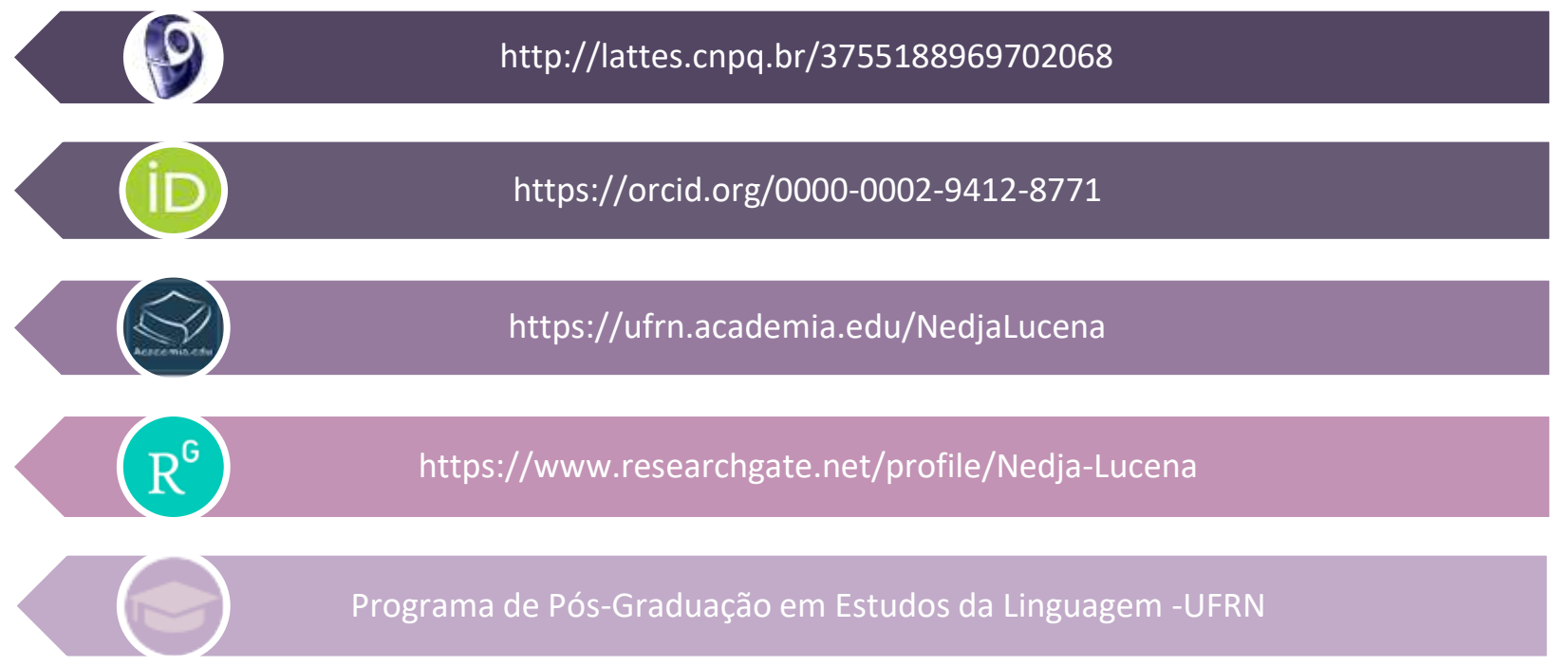

Grupo de Estudos Discurso \& Gramática

DOI: https://doi.org/10.32988/rep.v10n1.1269

Dossiê "Possibilidades de trabalho com a Língua Portuguesa"

\begin{tabular}{|l|l|l|l|l|l|l|}
\hline Revista (Entre Parênteses) & Alfenas, MG & v. 10 & n. 1 & $1-18$ & e021005 & 2021 \\
\hline
\end{tabular}




\title{
(")
}

ISSN 2238-4502

\section{PRECISAMOS FALAR SOBRE ENSINO DE GRAMÁTICA? PERCEPÇÕES E PERSPECTIVAS DA ABORDAGEM GRAMATICAL NO SERIDÓ-RN}

\author{
Jakeline Simões Gomes ${ }^{1}$ \\ Universidade Federal do Rio Grande do Norte \\ (sgjake28@gmail.com) \\ Nedja Lima de Lucena ${ }^{2}$ \\ Universidade Federal do Rio Grande do Norte \\ (nedja.lucena@ufrn.edu.br)
}

\section{Introdução}

É assente nas discussões no âmbito da Linguística Aplicada e nas diretrizes norteadoras da educação (como é o caso dos Parâmetros Curriculares Nacionais, da Base Nacional Comum Curricular e de alguns documentos das esferas estadual e municipal), que o processo de ensino e aprendizagem de língua portuguesa deve estar alicerçado numa perspectiva que assinala a linguagem como atrelada às práticas sociais cotidianas, de maneira que se preze uma formação crítica, democrática e cidadã dos alunos.

Ocorre que, por força da tradição, o ensino de língua é, muitas vezes, reduzido (e até confundido) ao ensino de gramática normativa (POSSENTI, 1996). Esta gramática, de tradição normativo-prescritiva, pode ser entendida como um conjunto de leis preceituadas para "o bem falar e o bem escrever", cujos parâmetros estão ancorados, em geral, na ideia de língua pura, na classe social de prestígio (de caráter econômico, político e cultural), na autoridade (de gramáticos e bons escritores), na lógica e na tradição histórica (ANTUNES, 2003).

Desse modo, no centro das atividades alicerçadas na gramática normativa, está o conhecimento e domínio operacional das suas normas constituintes. Essas normas estão atreladas à noção de normatividade e são consideradas as prescrições, as leis de como deve ser

\footnotetext{
${ }^{1}$ Graduanda em Letras Língua Portuguesa (UFRN). Bolsista de Iniciação Científica (PROPESQ/UFRN).

2 Doutora em Estudos da Linguagem - Linguística Aplicada. Professora adjunta de Língua Portuguesa (UFRN). Coordenadora do projeto Percepções sobre ensino e aprendizagem de gramática na Educação Básica do Seridó (Fase I), financiado pela PROPESQ/UFRN.
}

DOI: https://doi.org/10.32988/rep.v10n1.1269

Dossiê "Possibilidades de trabalho com a Língua Portuguesa"

\begin{tabular}{|l|l|l|l|l|l|l|}
\hline Revista (Entre Parênteses) & Alfenas, MG & v. 10 & n. 1 & $1-18$ & e021005 & 2021 \\
\hline
\end{tabular}




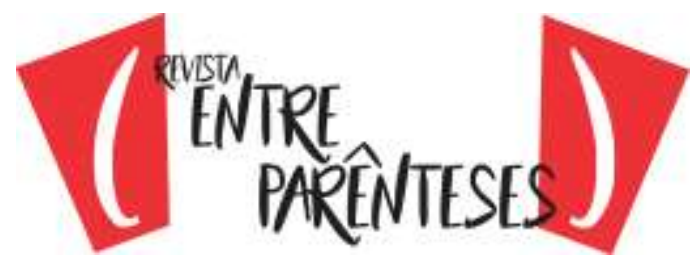

ISSN 2238-4502

a expressão linguística. Exercícios metalinguísticos de identificação e classificação teórica das nomenclaturas gramaticais, produção de textos sem propósito e sem direção apenas para usar as palavras da regra estudada, são amostras de atividades apoiadas nessa concepção gramatical (TRAVAGLIA, 2002).

Não raro, os estudantes ingressam nos cursos de Graduação, inclusive no curso de Letras, admitindo certa aversão aos estudos gramaticais. De certa forma, um programa de estudo pautado majoritariamente na gramática de tradição normativo-prescritiva, por estar distante da realidade linguística e social de grande parte dos alunos, torna-se ineficiente e impacta a percepção que o indivíduo tem de sua própria língua. Ao mesmo tempo, esse caminho para abordagem dos fenômenos gramaticais sequer encontra respaldo nos documentos norteadores da Educação Básica e/ou nas pesquisas linguísticas dos últimos trinta anos.

Diante desse contexto, desde meados da década de 1980, no âmbito da linguística brasileira, discute-se que a consequência desse tipo de trabalho é a saída da escola com uma visão de língua simplista, deturpada, reduzida e, muitas vezes, falseada e distante das práticas sociais efetivas de uso da linguagem. Estudiosos como Geraldi (1984), Neves (2010), Mendonça (2006), Antunes (2003; 2013), Vieira e Brandão (2019), dentre outros, advogam que a ação didático-pedagógica nas aulas de língua materna deve estar alicerçada numa perspectiva de língua em seu efetivo uso pelos sujeitos engajados nas situações sociocomunicativas. Desse modo, os fatos gramaticais devem ser questionados, investigados e atestados de acordo com o uso que os falantes fazem nas diversas práticas discursivas.

A partir da contribuição dos estudos da ciência da linguagem e da educação, as diretrizes educacionais (do âmbito federal ao municipal) para o ensino de língua portuguesa foram, em larga escala, reformuladas; programas de capacitação de professores foram criados; e a temática do ensino e aprendizagem de gramática - seja a sua defesa ou não - passou a figurar com mais veemência nas produções técnicas e científicas.

É a partir deste contexto profícuo de discussão que o presente trabalho se alicerça e intenta responder a seguinte questão de pesquisa: que discussões foram semeadas no âmbito da região do Seridó-RN quanto ao ensino e aprendizagem de gramática na escola? Para respondê-la, é necessário averiguar o lugar que o ensino de gramática assume nas práticas didático-pedagógicas, em especial, no cenário do Seridó potiguar, foco de nossa análise.

O Seridó, no estado do RN, é considerado uma mesorregião central que compreende 24 municípios $^{3}$, dentre os quais, destacam-se Caicó e Currais Novos. Em ambos há um campus da Universidade Federal do Rio Grande do Norte, sendo que se situa, em Currais Novos, o Departamento de Letras e a sede do Programa de Mestrado Profissional em Letras (PROFLETRAS).

\footnotetext{
${ }^{3}$ Currais Novos, Jardim do Seridó, Caicó, Parelhas, Jucurutu, Lagoa Nova, Jardim de Piranhas, Cerro Corá, Florânia, Carnaúba dos Dantas, Serra Negra do Norte, Cruzeta, São Vicente, São João do Sabugi, Equador, Tenente Laurentino Cruz, São José do Seridó, São Fernando, Timbaúba dos Batistas, Ipueira, Santa Cruz, Acari, Ouro Branco e Bodó.
}

DOI: https://doi.org/10.32988/rep.v10n1.1269

Dossiê "Possibilidades de trabalho com a Língua Portuguesa"

\begin{tabular}{|l|l|l|l|l|l|l|}
\hline Revista (Entre Parênteses) & Alfenas, MG & v. 10 & n. 1 & $1-18$ & e021005 & 2021 \\
\hline
\end{tabular}




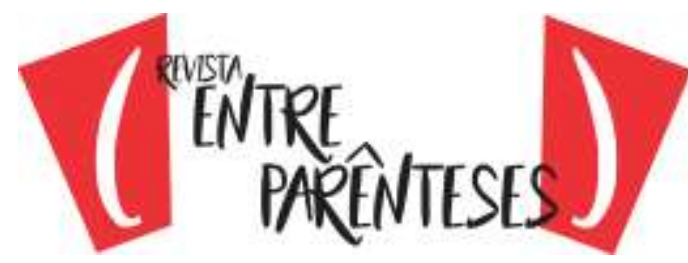

ISSN 2238-4502

Esse programa caracteriza-se por um curso presencial que conta com a participação de 42 Instituições de Ensino Superior, no contexto da Universidade Aberta do Brasil (UAB), tendo sua sede na Universidade Federal do Rio Grande do Norte. Além disso, o programa visa à capacitação de professores de Língua Portuguesa para o exercício da docência no Ensino Fundamental, com o intuito de contribuir para a melhoria da qualidade do ensino no País. Dessa forma, todos os trabalhos defendidos no PROFLETRAS abarcam uma reflexão e/ou proposta de intervenção sobre a sala de aula e o ensino de Língua Portuguesa, através da pesquisa-ação que propicia o desenvolvimento dessa proposta perante o uso de sequências didáticas (DOLZ; NOVERRAZ; SCHNEWLY, 2004).

Dada a localização geográfica do PROFLETRAS - Currais Novos, selecionamos as dissertações produzidas no âmbito desse programa como fonte de dados para este estudo qualitativo e documental. 0 banco de dados é composto por 67 dissertações, produzidas entre 2015 e 2020. A partir do esquadrinhamento teórico e metodológico, reunimos 12 dissertações que servem como base para a discussão empreendida neste artigo.

0 texto organiza-se da seguinte maneira: após as considerações iniciais, tecemos uma reflexão sobre o ensino de gramática, assinalando aspectos ressaltados no referencial teórico e nos documentos que balizam a Educação Básica no país; em seguida, apresentamos os procedimentos metodológicos para o tratamento dos dados coletados; posteriormente, evidenciamos as percepções sobre gramática que os textos analisados permitem entrever; na esteira disso, empreendemos uma reflexão sobre estas e apresentamos as considerações finais.

A gramática na escola: notas sobre uma defesa

Um dos propósitos do ensino de língua portuguesa na escola é a ampliação de todas as competências previstas pela atividade verbal. Isso significa aprimorar o repertório linguístico e sociocultural dos alunos, preservando, respeitando e valorizando a diversidade linguístico-cultural, bem como permitindo a leitura e a produção de textos orais e escritos de qualquer dimensão, de maneira que eles possam interagir em situações mais ou menos formais, tanto como falantes/produtores como ouvintes/leitores de textos (ANTUNES, 2014).

Em outras palavras, de acordo com Travaglia (2002), a competência linguística envolve a habilidade de usar a língua nos mais variados contextos sociocomunicativos com o intuito de alcançar os propósitos e efeitos de sentido ensejados e, ainda, abrange a reflexão e análise sobre os fatos da língua, permitindo que os usuários tenham conhecimento descritivo e explicativo para escolher, de acordo com a intenção pretendida, as formas linguísticas que melhor se encaixem em seus propósitos.

Esse ponto de vista e preocupação com a formação de usuários competentes linguisticamente levou à recomendação "de que o ensino sobre a língua, e consequentemente, de teoria gramatical, seja posto em segundo plano em termos de importância” (TRAVAGLIA,

DOI: https://doi.org/10.32988/rep.v10n1.1269

Dossiê "Possibilidades de trabalho com a Língua Portuguesa"

\begin{tabular}{|l|l|l|l|l|l|l|} 
Revista (Entre Parênteses) & Alfenas, MG & v. 10 & n. 1 & $1-18$ & e021005 & 2021 \\
\hline
\end{tabular}




\section{("Eintrere}

ISSN 2238-4502

2002, p. 137). Ocorre que, em nossa prática docente no âmbito dos cursos de Letras, deparamonos com estudantes preocupados sobre se devem ou não ensinar gramática na escola. Nesse viés, a dúvida perpassa duas questões fundamentais: qual gramática ensinar e como ensiná-la sem cair na armadilha de torná-la o centro das atividades.

Entendemos, conforme já assinalado na introdução deste trabalho, que o ensino de gramática como centro da atividade pedagógica na aula de língua portuguesa já provou ser ineficiente. $\mathrm{O}$ foco em atividades metalinguísticas não fornece os subsídios necessários para a leitura e produção de textos, sobretudo, quando pensamos na diversidade de gêneros discursivos que nos cercam e nos exigem uma atitude responsiva, enquanto leitores/ouvintes, e autoral, enquanto produtores.

As atividades metalinguísticas são aquelas cujo foco está em conceitos, classificações e outras operações sistemáticas. Apenas para ilustrar, um emblemático estudo realizado por Maria H. M. Neves, na década de 90, demonstrou que, em São Paulo, os exercícios de reconhecimento e classificação de classes de palavras e de funções sintáticas ocupavam, à época, $75 \%$ das atividades de ensino de gramática. Excluídas as atividades que envolviam leitura e produção de textos, o percentual crescia para quase 90\%, se consideradas atividades de ortografia, acentuação, fonética e fonologia e morfologia. Por hipótese, arriscamos que, quase vinte anos depois, o cenário tem mudado, no entanto, é possível que ocorra, em alguns espaços escolares, o foco no ensino da metalinguagem gramatical. Decorre disso, a pergunta que enceta este texto: precisamos falar sobre o ensino de gramática?

Compreendemos gramática como o conjunto de saberes que todo indivíduo, quando coloca sua língua materna em funcionamento, conhece, isto é, os padrões linguísticos emergentes e ritualizados pelo próprio uso linguístico (BISPO; SILVA, 2011). Isso implica dizer que fazemos coro com nossos pares que defendem a não existência de manifestação linguística ausente de gramática, ou seja, não há língua sem gramática e, nem gramática fora da língua, conforme assinalam Antunes (2007), Travaglia (2002) e outros.

A gramática, sendo uma consequência do uso, regula muito, mas não regula tudo, uma vez que nem todas as prescrições cabem no seu domínio (ANTUNES, 2013). Não se pode abandonar a investigação gramatical, mas é urgente mudar o seu caminho e endireitar suas veredas. Isso só pode acontecer ao pensar essa investigação por meio de dados empíricos, ou seja, através da análise de textos orais e escritos pertencentes a gêneros textuais/discursivos diversos, uma vez que apenas no texto a gramática faz sentido.

Nesse viés, é necessário evidenciar o que entendemos por ensino de gramática. Primeiramente, consideremos que o rótulo "ensino de gramática", muitas vezes, é interpretado como sinônimo de ensino de uma norma padrão ou até mesmo como mecanismo de controle sobre o que não se deve ensinar na escola. Martins (2017, p. 105) aponta que essa interpretação equivocada sobre o ensino de gramática "desloca a questão ou para um ensino normativo da língua - da gramática como norma padrão - ou para o abandono completo do ensino da norma padrão assim como da própria gramática".

DOI: https://doi.org/10.32988/rep.v10n1.1269

Dossiê "Possibilidades de trabalho com a Língua Portuguesa"

\begin{tabular}{|l|l|l|l|l|l|l} 
Revista (Entre Parênteses) & Alfenas, MG & v. 10 & n. 1 & $1-18$ & e021005 & 2021 \\
\hline
\end{tabular}




\section{(")}

ISSN 2238-4502

Em segundo lugar, esse equívoco de longa data levou-nos a referenciar o ensino de gramática como análise linguística (GERALDI, 1984), numa postura que carrega em si o estatuto ideológico de se distinguir do estigma que a expressão ensino de gramática - como ensino de uma norma padrão idealizada - tem assumido ao longo dos últimos anos, o que pode ser atestado inclusive em documentos como Parâmetros Curriculares Nacionais (PCN) e Base Nacional Comum Curricular (BNCC).

A prática de análise linguística remete a um modo de refletir sobre os fatos gramaticais, tendo como alicerce uma teoria que observe o uso linguístico e uma metodologia que abrigue o espaço para a reflexão, questionamento e efeitos de sentidos que os usos podem assumir nas diferentes esferas da comunicação humana (BEZERRA; REINALDO, 2013). Desse modo, esclarecemos: quando referimos ao ensino de gramática neste trabalho, entendemos que este envolve a prática de análise linguística nos mais variados contextos de uso e se desvincula de uma abordagem gramatical com vistas à ideia de uma norma-padrão que só existe no imaginário popular (FARACO, 2006). Diante disso, para fins de referenciação, assumimos, neste artigo, os termos ensino de gramática e análise linguística como sinônimos.

A título de exemplo, a BNCC (BRASIL, 2017), documento norteador mais recente da educação brasileira, menciona que a análise linguística deve se desenvolver "transversalmente aos dois eixos - leitura/escuta e produção oral, escrita e multissemiótica - o que envolve a análise textual, gramatical, lexical, fonológica e das materialidades das outras semioses" (p. 80). Essa visão se coaduna com o referencial teórico aqui adotado, na medida em que abrange a consciência de que as formas linguísticas devem ser investigadas à luz da materialidade discursiva, isto é, balizada pelos gêneros discursivos (orais, escritos e multissemióticos) e não como centro da aula de português, mas como apoio ao entendimento dos efeitos de sentidos construídos.

Considerando que as práticas de leitura, produção textual, oralidade e análise linguística são as unidades básicas de ensino e aprendizagem, é fulcral ampliar o domínio dessas práticas no cotidiano escolar. Franchi, Negrão e Müller (2006) defendem que é essencial levar o aluno a saber operar sobre a língua, de forma que ele consiga recuperar a dimensão de uso da linguagem em situações interativas. Estabelece-se, assim, uma diferenciação entre atividade linguística, que corresponde ao exercício pleno e situado da linguagem; atividade epilinguística, que resulta da reflexão sobre o uso de recursos expressivos em situações de interlocução; e atividade metalinguística, que tomam a linguagem como objeto de reflexão já não balizadas no processo de interlocução por serem atividades que visam à construção de conceitos, classificações ou categorias. Nas palavras dos autores (2006, p. 88), é essencial no campo da investigação gramatical "estudar a variedade dos recursos sintáticos expressivos, colocados à disposição do falante ou do escritor para a construção do sentido. Repetindo: gramática é o estudo das condições linguísticas da significação".

Na esteira disso, cabe observar como os fenômenos gramaticais contribuem para os efeitos de sentido nas mais variadas composições textuais. Com o intuito de elucidar a discussão

DOI: https://doi.org/10.32988/rep.v10n1.1269

Dossiê "Possibilidades de trabalho com a Língua Portuguesa"

\begin{tabular}{|l|l|l|l|l|l|l} 
Revista (Entre Parênteses) & Alfenas, MG & v. 10 & n. 1 & $1-18$ & e021005 & 2021 \\
\hline
\end{tabular}




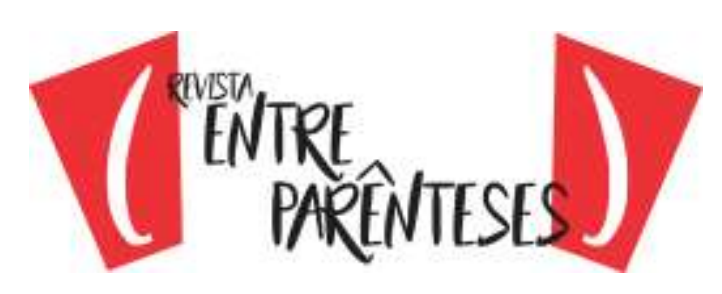

ISSN 2238-4502

podem assinalar; por que e como foram selecionados para ocupar aquele espaço no texto; quais suas funções e que pretensões comunicativas respondem, apenas para citar alguns caminhos. Em suma, a investigação dos recursos linguístico-discursivos mobilizados nos diversos gêneros textuais/discursivos permite o entendimento de como tais recursos suscitam inferências, emoções e efeitos de sentido do texto. Isso porque pensar o ensino de gramática é ir além dos aspectos morfossintáticos, posto que é necessário levar em conta os aspectos semânticodiscursivos das unidades linguísticas na formação de enunciados.

Metodologia

Este estudo configura-se, em termos metodológicos, como de abordagem qualitativa, cuja interpretação dos fenômenos e a atribuição de significados (SILVA; MENEZES, 2005, p. 20) são basilares no processo de investigação. Quanto à sua natureza técnica, ancorase na pesquisa documental e na pesquisa bibliográfica.

De acordo com Kripka, Scheller e Bonotto (2015), a análise documental pode ser tomada como uma série de operações que objetiva examinar um ou vários documentos, com o intuito de que sejam identificadas informações factuais, circunstâncias sociais, econômicas e ecológicas com as quais pode (m) estar relacionado(s), concentrando-se, ainda, nas questões de interesse de pesquisa, no caso do estudo realizado aqui, centramo-nos no ensino de gramática.

O levantamento documental, em geral, considera como fontes: dados primários, documentos de arquivos públicos, publicações administrativas, estatísticas, relatos de visitas a instituições, entre outros; e dados secundários, por exemplo, relatórios de pesquisa baseados em trabalhos de campo, estudo histórico, diários de observação, dissertações, teses, trabalhos de conclusão de curso etc. Sendo assim, esta pesquisa utilizou fontes secundárias, uma vez que mapeou o conjunto de dissertações defendidas no âmbito do PROFLETRAS - Currais Novos, vinculado à Universidade Federal do Rio Grande do Norte. A empiria da pesquisa é formada por uma coleção de dados, que abarca 67 documentos publicados entre os anos de 2015 a 2019.

A partir do tratamento metodológico e da garimpagem de dados, selecionamos as produções executadas no âmbito do Seridó, isto é, em que o locus da pesquisa descrita nas dissertações estivesse nessa região. Além disso, elegemos os trabalhos que tratavam, em alguma medida, do ensino de gramática, seja em sua discussão teórica ou na sequência didática analisada ou realizada.

As dissertações (D) receberam uma classificação numérica aleatória que serve como base para sua referência e, para este trabalho, preservamos a identidade dos sujeitos e das instituições envolvidas. Quanto aos critérios de exame preliminar dos dados coletados, consideramos: (1) a área de concentração da pesquisa, de modo que esta estivesse circunscrita ao âmbito da Linguística; (2) a localização geográfica da instituição de ensino retratada no

DOI: https://doi.org/10.32988/rep.v10n1.1269

Dossiê "Possibilidades de trabalho com a Língua Portuguesa"

\begin{tabular}{|l|l|l|l|l|l|l} 
Revista (Entre Parênteses) & Alfenas, MG & v. 10 & n. 1 & $1-18$ & e021005 & 2021 \\
\hline
\end{tabular}




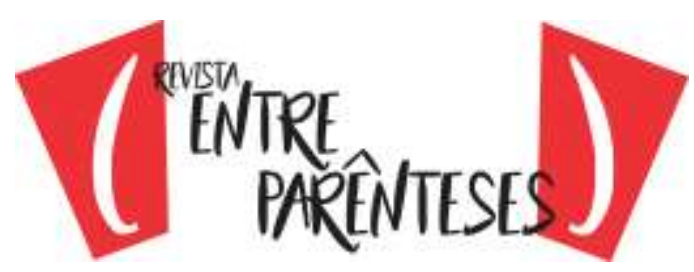

ISSN 2238-4502

estudo e (3) os temas elencados na discussão teórica e na sequência didática, priorizando a busca por menções ao ensino de gramática e à abordagem de fatos gramaticais.

Excluídos os documentos que não estavam circunscritos nos critérios adotados, selecionamos 12 dissertações que servem como foco desta análise, uma vez que estas contemplam os critérios metodológicos assumidos no exame aqui empreendido.

Análise dos resultados: percepções sobre ensino de gramática

O conjunto de dados analisados descreve sequências didáticas que contemplam assuntos gramaticais, tais como: pronomes, substantivos, verbos, adjetivos, advérbios, classes de palavras de modo geral, frase, oração, período, termos da oração, regência, concordância nominal e verbal e coesão e coerência.

$\mathrm{Na}$ construção do texto dissertativo, percebe-se menção à discussão teórica em torno do ensino de gramática, tecendo críticas ao estudo normativo-prescritivo, como descrito em (D23), (D34), (D47), (D56) e (D61). Observe-se uma amostra da percepção que o docente apresenta acerca desse tipo de abordagem gramatical:

(1) Entendemos que o ensino de línguas que prioriza as nomenclaturas ou regras gramaticais não é atrativo, nem gera eficiência comunicativa porque em situações de interação linguística os interlocutores não estão preocupados em discutir se uma palavra proferida é oxítona, se é derivada ou se exerce a função de sujeito dentro da oração. (D-23).

Em (1), destaca-se que o estudo centrado na metalinguagem é ineficiente, conforme tem advogado o referencial teórico adotado ao longo deste trabalho. Nesse caminho, a metalinguagem é uma consequência do estudo analítico da língua, mas não deve figurar no centro dela. Em (2), o professor ressalta seu ponto de vista a respeito disso:

(2) Não se pode fazer da nomenclatura gramatical um requisito para a aprendizagem de regras (contextuais e morfológico-gramaticais), pois ao discutir regras de compreensão metalinguística não devemos exigir que os alunos saibam usar termos difíceis ou terminologias especializadas. (D-63).

É interessante observar como esses professores, na condição de alunos da pósgraduação, buscam por um ensino de gramática que sirva de apoio à ação didático-pedagógica, sendo, em relação às habilidades de leitura e produção de textos, suporte para a melhoria das capacidades de leitura e produção de textos. De modo geral, percebe-se que todos os trabalhos

DOI: https://doi.org/10.32988/rep.v10n1.1269

Dossiê "Possibilidades de trabalho com a Língua Portuguesa"

\begin{tabular}{|l|l|l|l|l|l|l|} 
Revista (Entre Parênteses) & Alfenas, MG & v. 10 & n. 1 & $1-18$ & e021005 & 2021 \\
\hline
\end{tabular}




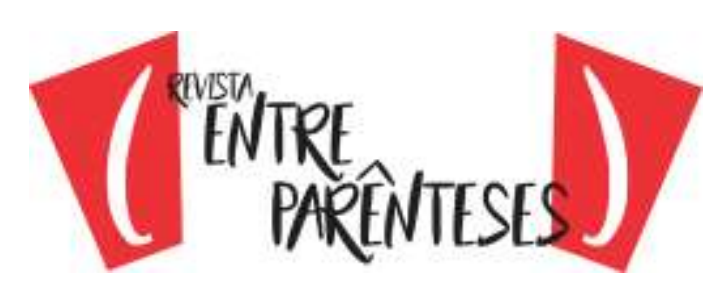

ISSN 2238-4502

abordam, em especial na seção de fundamentação teórica, a necessidade de um estudo de gramática de modo contextualizado, ao passo que centram essa discussão com referências a pesquisadores como Irandé Antunes, Maria Helena de Moura Neves, Roxane Rojo, Sírio Possenti, Marcos Bagno, Carlos Alberto Faraco, Luiz Carlos Travaglia.

A respeito disso, observe-se a afirmação feita pelo docente:

(3) Não se trata de disfarçar o ensino de gramática com uma nova nomenclatura, trata-se de permitir aos aprendizes a reflexão e a tomada de consciência dos fenômenos enunciativos da língua, proporcionando a estes uma visão mais funcional da língua. (D61).

Consideramos tal reflexão positiva e evidenciamos que é permanente a defesa sobre um olhar para o fenômeno gramatical de modo diferenciado. Nota-se, assim, para a aula de português, uma abordagem que considera concepções como gramática internalizada (D10), gramática funcional (D61), gramática contextualizada (D34) e gramática de uso (D34).

Os pontos ressaltados nos dados demonstram que os professores possuem postura crítica acerca do ensino de gramática e de como este deve ser ressignificado, sobressaindo-se do estereótipo de que a gramática deve ser ensinada apenas nos moldes normativos. No entanto, é preciso considerar, conforme Travaglia (2002), que qualquer aspecto da língua é passível de uma abordagem teórica e não teórica ou normativa.

Um ponto que nos interessa questionar se a fundamentação teórica apontada como escopo revela-se na prática escolar evidenciada? Em outras palavras, o tratamento dado ao fenômeno gramatical tem ido além de uma abordagem prescritiva? Nesse viés, entendemos que a gramática serve às manifestações discursivas, assim, sua abordagem deve se pautar nos usos consubstanciados nos diversos gêneros orais e escritos que circulam na comunidade linguística. Em coro conosco, veja-se a percepção docente a seguir:

(4) A gramática que está em função do texto, ou seja, está a serviço dos gêneros de discurso e é responsável pela organização das relações que constroem os sentidos e determinam as escolhas linguísticas. (D10).

Ao tecer essa afirmação, é notável a consciência de que a gramática deve ser contextualizada e, para isso, deve compor o amplo espectro possível a partir das sequências didáticas. No entanto, o que se nota, em algumas passagens dos dados analisados, é uma iniciativa de contextualizar o fenômeno gramatical, mas que, por alguma razão, acaba por resvalar numa visão tradicional. A título de exemplo, o texto em D44 objetiva tratar, na sequência didática, de alguns aspectos gramaticais, como substantivos, adjetivos e pronomes. Embora haja atividades envoltas pela leitura e a produção de texto, os assuntos destacados, por

DOI: https://doi.org/10.32988/rep.v10n1.1269

Dossiê "Possibilidades de trabalho com a Língua Portuguesa"

\begin{tabular}{|l|l|l|l|l|l|l} 
Revista (Entre Parênteses) & Alfenas, MG & v. 10 & n. 1 & $1-18$ & e021005 & 2021 \\
\hline
\end{tabular}




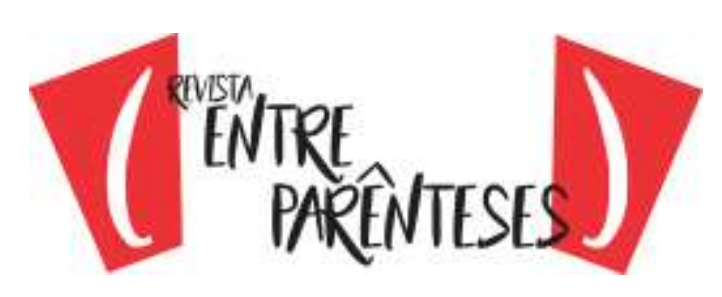

ISSN 2238-4502

vezes, são ministrados explicitando apenas os conceitos e, em seguida, com a solicitação de exemplos de classes de palavras classificadas como substantivos, além de atividades na modalidade escrita, consistindo em copiar da lousa as perguntas sobre conteúdos gramaticais, como os pronomes. 0 relato demonstra que não foi feita uma menção sobre a funcionalidade desses elementos no texto para a criação de efeitos de sentidos.

Sobre isso, destacamos a ótica apresentada em D54:

(5) Devemos utilizar o texto, principalmente, nas aulas de Língua Portuguesa, não como pretexto para trabalhar atividades gramaticais, mas como meio de aproximação entre autor e leitor, propiciando a formação do sujeito-leitor. (D54).

Nesse dado, em especial, percebemos que, na sequência didática empreendida, os conteúdos gramaticais são enfocados de modo mais livre e confortável, priorizando a discussão oral através de rodas de conversas e permitindo aos alunos, explorar os aspectos gramaticais por meio da leitura de crônicas, em que poderiam conversar sobre os efeitos de sentidos criados a partir das escolhas linguísticas.

Encontramos, na D-39, uma sequência didática cuja concepção de leitura vincula-se à prática social. Nesse dado, priorizam-se os fenômenos da coesão e da coerência e, na metodologia empregada pelo docente, explora-se

(6) sete descritores, que dizem respeito às ligações de sentidos, tanto ao nível micro quanto ao nível macrotextual, ou seja, de que forma os recursos gramaticais estabelecem, por exemplo, as relações de continuidade do texto [...] A palavra de ordem neste tópico é o estabelecimento de relações semânticas, ou seja, relações de sentido no texto. (D39).

Nessa sequência, percebe-se de modo mais claro uma preocupação em buscar os efeitos de sentidos atribuídos aos elementos linguísticos que compõem o tecido textual e cooperam para a significação.

A percepção docente empreendida na amostra D34 assinala que

(7) [...] os alunos requerem sempre, um pouco de metalinguagem para que compreendam as atividades de gramática contextualizadas. [...] Não convém dissociar gramática e texto, rompendo uma tradição gramatical ainda arraigada, mas deve-se oferecer um olhar crítico sobre as categorias gramaticais comumente descritas nos manuais, levando assim o aluno a lançar mão dos textos para pensar a língua. (D34).

DOI: https://doi.org/10.32988/rep.v10n1.1269

Dossiê "Possibilidades de trabalho com a Língua Portuguesa"

\begin{tabular}{|l|l|l|l|l|l|l|}
\hline Revista (Entre Parênteses) & Alfenas, MG & v. 10 & n. 1 & 1 -18 & e021005 & 2021 \\
\hline
\end{tabular}




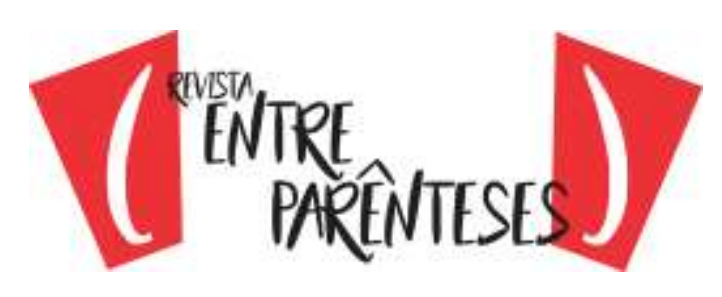

ISSN 2238-4502

Os dados apontam para um ensino que contém, ainda, resquícios de uma pedagogia pautada na gramática normativa, mas assinalam evidências de ações didático-pedagógicas voltadas para um ensino de língua que une os usos linguísticos à dinâmica funcionalidade dos gêneros discursivos.

Sendo assim, percebe-se que muitos docentes são conscientes da necessidade de um ensino que alie a teoria à prática, todavia, às vezes, falta-lhes o conhecimento técnico para isso, ou até mesmo um aprofundamento teórico acerca de como funciona o fenômeno da linguagem humana (ANTUNES, 2003), ocasionando, de certo modo, uma certa confusão sobre o que é realmente ensinar gramática. Diante disso, pode-se refletir que, de um lado temos a teoria - que, por vezes, busca defender e incentivar uma postura crítica do professor frente aos conteúdos e metodologias, e de outro lado, no entanto, a prática em sala de aula que desencadeia ao professor um posicionamento contrário, pois mesmo com os avanços do ensino de língua portuguesa e de uma abordagem que permeia o ensino de gramática em sala de aula, delineia-se, afinal, um ensino de "aparências", em que se prioriza a teoria e "anula-se" a prática.

Entendemos que, para um ensino de língua operacional e reflexivo, uma alternativa útil, que vem sendo discutida desde o trabalho de Dolz, Noverraz e Schneuwly (2004), remete à proposta com as sequências didáticas, em que a criação de contextos de produção significativos, atrelados à diversidade de atividades que englobem múltiplas competências e habilidades, permite aos estudantes a apropriação de noções, técnicas e instrumentos necessários ao desenvolvimento de suas capacidades de expressão oral e escrita em situações de comunicação diversas.

Assim, retomamos à questão que enceta o presente texto: "precisamos falar sobre ensino de gramática?". Advogamos que sim, é necessária a discussão sobre as bases da ação didático-pedagógica nas aulas de língua materna e isso perpassa o investimento na formação dos professores e dos futuros professores que compõem e comporão, respectivamente, 0 quadro de profissionais que pensam a linguagem na escola.

É evidente que o tratamento da gramática na sala de aula, documentado nas produções científicas da região do Seridó, permeia um avanço na postura dos professores sobre o ensino de gramática. Sobre isso, advogamos que o programa PROFLETRAS tem contribuído bastante para a melhoria da formação dos professores que atuam nas salas de aulas desse país. No caso da região aqui analisada, observamos que os avanços empreendidos se devem, sobremaneira, ao trabalho realizado na formação no âmbito do Mestrado Profissional.

\section{Considerações finais}

Esta pesquisa buscou discutir e retratar, por meio da investigação documental e bibliográfica, como tem se configurado o ensino e aprendizagem de gramática na região do Seridó-RN, através das produções científicas do PROFLETRAS.

DOI: https://doi.org/10.32988/rep.v10n1.1269

Dossiê "Possibilidades de trabalho com a Língua Portuguesa"

\begin{tabular}{|l|l|l|l|l|l|l|} 
Revista (Entre Parênteses) & Alfenas, MG & v. 10 & n. 1 & $1-18$ & e021005 & 2021 \\
\hline
\end{tabular}




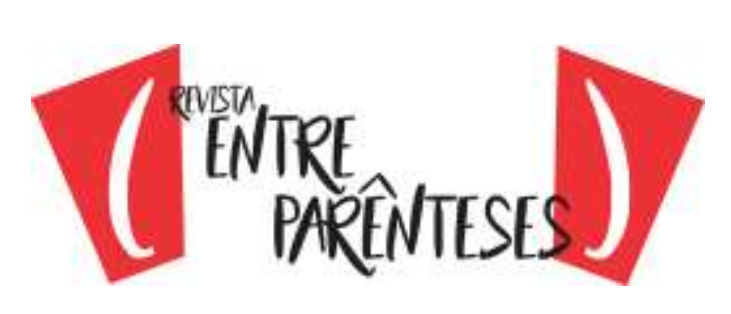

ISSN 2238-4502

Os dados obtidos no estudo demonstram um avanço no âmbito do ensino de gramática; no entanto, mesmo em trabalhos que buscam abordar os fenômenos gramaticais, essa abordagem resvala numa perspectiva mais normativa e prescritiva. Por hipótese, notamos que esse resultado pode estar relacionado a (i) um certo receio de trabalhar com a investigação gramatical, pois o tema de ensino de gramática é, ainda, estigmatizado; ou (ii) isso evidencie uma certa inabilidade em relacionar fenômenos gramaticais a práticas contextualizadas de leitura e produção de textos.

De tal modo, essas produções, no que concerne ao ensino e aprendizagem de gramática, suscitam dados de grande valia sobre a temática investigada, podendo futuramente serem analisadas em meio a novas óticas, além de visar possibilidades de produção de novos trabalhos pedagógicos voltados para processo de ensino e aprendizagem de gramática no âmbito do Seridó. Por essa razão, destacamos que é necessário que se fale sobre gramática para desmistificar o mito de que esta é algo separado e distante das práticas de leitura e produção de textos, ao contrário, a gramática reflete-se e está evidente em todos os usos linguísticos que nós, falantes, construímos no cotidiano.

\section{Referências}

ANTUNES, I. Aula de português: encontro \& interação. São Paulo: Parábola, 2003.

Muito além da gramática: por um ensino de línguas sem pedras no caminho. São Paulo: Parábola, 2007.

Muito além da gramática. São Paulo: Parábola Editorial, 2013.

Gramática contextualizada: limpando o pó das ideias simples. São Paulo: Parábola Editorial, 2014.

BRASIL. Base Nacional Comum Curricular: Educação Infantil e Ensino Fundamental. Brasília: MEC/Secretaria de Educação Básica, 2017. BRASIL.

BEZERRA, M. A.; REINALDO, M.A. Análise linguística: afinal, a que se refere? São Paulo: Cortez, 2013a.

BEZERRA, M. A. Conceitos de análise linguística associados a teorias de gênero. In: SILVA, Sílvio Ribeiro da; APARÍCIO, A. S. M. (Org.). Ensino de língua materna e formação docente: teoria, didática e prática. Campinas: Pontes Editores, 2013b.

BISPO, E. B.; SILVA, J. R. Análise linguística na educação básica: entre o real e o possível. In: Simpósio Internacional de Ensino da Língua Portuguesa, 2011, Uberlândia. Anais do SIELP. Uberlândia: EDUFU, 2011. v. 1, n. 1, p. 282-294.

DOLZ, Joaquim; NOVERRAZ, Michele; SCHNEUWLY, Bernard. Seqüências didáticas para o oral e a escrita: apresentação de um procedimento. In: SCHNEUWLY, Bernard; DOLZ, Joaquim.

DOI: https://doi.org/10.32988/rep.v10n1.1269

Dossiê "Possibilidades de trabalho com a Língua Portuguesa"

\begin{tabular}{|l|c|c|c|c|c|c|}
\hline Revista (Entre Parênteses) & Alfenas, MG & v. 10 & n. 1 & $1-18$ & e021005 & 2021 \\
\hline
\end{tabular}




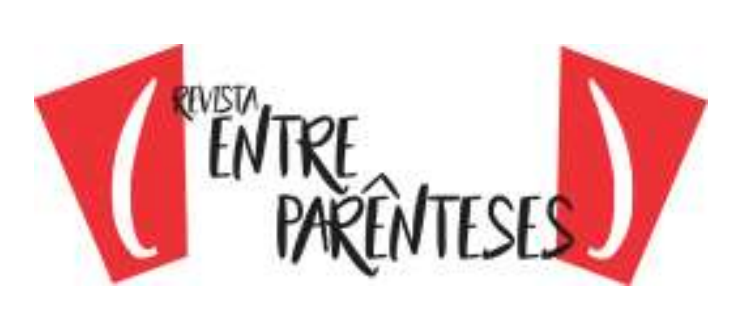

ISSN 2238-4502

Gêneros orais e escritos na escola. Tradução de Roxane Rojo e Glaís Sales Cordeiro. Campinas, SP: Mercado das Letras, 2004, p. 95-128.

FARACO, C. A. Ensinar x Não ensinar gramática: ainda cabe essa questão?. Calidoscópio, v. 4, n. 1, p. 15-26, 2006.

FRANCHI, C.; NEGRÃO, E. V.; MULLER, A. L. P. Mas o que é mesmo gramática? São Paulo: Parábola, 2006.

GERALDI, J. W. (Org.). 0 texto na sala de aula: leitura e produção. Cascavel: Assoeste, 1984. KRIPKA, R. M.; SCHELLER, M; BONOTTO, D. L. Pesquisa documental na pesquisa qualitativa: conceitos e caracterização. Revista de investigaciones UNAD, v. 14, n. 1, p. 55-73, 2015.

MARTINS, M. A. Em defesa do ensino de gramática. Revista do GELNE, v. 19, n.1, p. 103-117, 2017.

MENDONÇA, M. (Orgs.). Português no ensino médio e formação do professor. São Paulo: Parábola Editorial, 2006. p.199-226.

MONTEIRO, J. L. A estilística: manual de análise e criação do estilo literário. Edição: 2. ed. Petrópolis-RJ: Vozes, 2009.

NEVES, M. H. M. Que gramática estudar na escola? Norma e uso na língua portuguesa. São Paulo: Contexto, 2003.

Gramática na escola: renovação do ensino da gramática, formalismo x funcionalismo, análise da gramática escolar. Edição: 8. ed. São Paulo: Contexto, 2010.

POSSENTI, S. Por que (não) ensinar gramática na escola. Campinas: Mercado das Letras, 1996.

RAMALHO, Christina. Fio de teNsão. São Paulo: Benfazeja, 2017.

SILVA, E.; MENEZES, E. Metodologia da Pesquisa e elaboração de dissertação.

Florianópolis: UFSC, 2005.

TRAVAGLIA, L. C. Para que ensinar teoria gramatical. Revista de Estudos da Linguagem, v.10, n. 2, p.135-231, 2002.

VIEIRA, S. R; BRANDÃO, S. F. Ensino de gramática: descrição e uso. São Paulo: Contexto, 2019.

Recebido em 20/10/2020

Aceito em 26/01/2021

Publicado em 30/06/2021

DOI: https://doi.org/10.32988/rep.v10n1.1269

Dossiê "Possibilidades de trabalho com a Língua Portuguesa"

\begin{tabular}{|l|l|l|l|l|l|l|} 
Revista (Entre Parênteses) & Alfenas, MG & v. 10 & n. 1 & $1-18$ & e021005 & 2021 \\
\hline
\end{tabular}




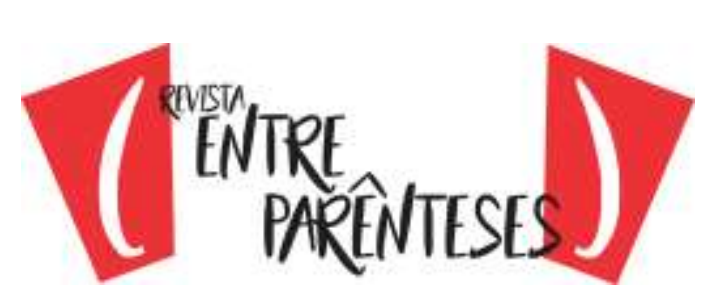

ISSN 2238-4502

\title{
DO WE NEED TO TALK ABOUT GRAMMAR TEACHING? PERCEPTIONS AND PERSPECTIVES OF THE GRAMMATICAL APPROACH IN THE SERIDÓ-RN
}

\author{
Jakeline Simões Gomes \\ Universidade Federal do Rio Grande do Norte \\ (jakegomes@ufrn.edu.br) \\ Nedja Lima de Lucena \\ Universidade Federal do Rio Grande do Norte \\ (nedjalucena@ufrn.edu.br)
}

\begin{abstract}
This paper discusses aspects related to the teaching and learning of grammar within the scope of Basic Education in the region of Seridó, in the state of Rio Grande de Norte (RN). It aimed to map the perceptions about teaching grammar from dissertations produced under the Professional Master's Program in Letras. Theoretically, the study is based on Travaglia (2002), Antunes (2003), Faraco (2006), Neves (2010), Bispo e Silva (2011), Vieira and Brandão (2019), among others. The results obtained demonstrate that, despite the advances regarding the approach to the grammatical phenomenon in Portuguese language classes, there is still a difficulty in linking grammatical reflection to reading and text production practices.
\end{abstract}

Keywords: Grammar teaching. Portuguese language class. Contextualized grammar.

DOI: https://doi.org/10.32988/rep.v10n1.1269

Dossiê "Possibilidades de trabalho com a Língua Portuguesa"

n. 1

$1-18$




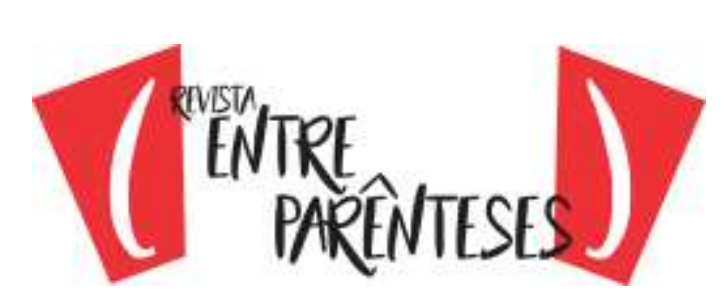

ISSN 2238-4502

\title{
¿NECESITAMOS HABLAR SOBRE LA ENSEÑANZA DE LA GRAMÁTICA? PERCEPCIONES Y PERSPECTIVAS DEL ENFOQUE GRAMMÁTICO EN LO SERIDÓ-RN
}

\author{
Jakeline Simões Gomes \\ Universidade Federal do Rio Grande do Norte \\ (jakegomes@ufrn.edu.br) \\ Nedja Lima de Lucena \\ Universidade Federal do Rio Grande do Norte \\ (nedjalucena@ufrn.edu.br)
}

\begin{abstract}
Resumen
En este trabajo se discuten aspectos relacionados con la enseñanza y aprendizaje de la gramática en el ámbito de la Educación Básica en la región de Seridó, en el estado de Rio Grande de Norte (RN). Su objetivo era mapear las percepciones sobre la enseñanza de la gramática a partir de las disertaciones elaboradas en el marco del Programa de Maestría Profesional en Letras. Teóricamente, el estudio se basa en Travaglia (2002), Antunes (2003), Faraco (2006), Neves (2010), Bispo e Silva (2011), Vieira y Brandão (2019), entre otros. Los resultados obtenidos demuestran que, a pesar de los avances en el abordaje del fenómeno gramatical en las clases de lengua portuguesa, aún existe una dificultad para vincular la reflexión gramatical con las prácticas de lectura y producción de textos.
\end{abstract}

Palabras clave: Enseñanza de la gramática. Clases de lengua portuguesa. Gramática contextualizada.

DOI: https://doi.org/10.32988/rep.v10n1.1269

Dossiê "Possibilidades de trabalho com a Língua Portuguesa"

\begin{tabular}{|l|l|l|l|} 
Revista (Entre Parênteses) & Alfenas, MG & v. 10 & n. 1 \\
\hline
\end{tabular}

